\title{
Critical liquid-carrying model for horizontal gas well
}

\author{
Shuangquan Liu ${ }^{1}$, Xiongxiong Wang ${ }^{1}, \mathrm{Li} \mathrm{Li}^{1}$, Jianshe Feng ${ }^{1}$, Ruiquan $\mathrm{Liao}^{2,3,}{ }^{*}$, Xiuwu Wang ${ }^{2,4}$ \\ ${ }^{1}$ Oil \& Gas Technology Research Institute of Changqing Oilfield Company, Xi'an 710000, China \\ 2 Yangtze University, Wuhan 430100, China \\ ${ }^{3}$ Gas Lift Innovation Center, CNPC, Hubei 430100, China \\ ${ }^{4}$ Kunming University of Science and Technology, Kunming 650500, China
}

Corresponding Author Email: liaoruiquan@163.com

https://doi.org/10.18280/ijht.360419

Received: 5 March 2018

Accepted: 7 July 2018

\section{Keywords:}

horizontal gas well, liquid carrying, gas flow, liquid loading

\begin{abstract}
To identify the accurate gas volume to carry liquid in horizontal gas well, this paper simulates the gas-liquid two-phase flow in a single pipe on the platform of multiphase pipe flow. Through indoor experiments on gas-liquid two-phase flow, it is confirmed that the inclined section (inclined angle: $45^{\circ} \sim 60^{\circ}$ ) is mostly likely to suffer from liquid loading in horizontal gas well. Then, a new critical liquid-carrying model was built after fitting the liquid holdup calculation formula at different inclined angles, considering the actual liquid-carrying phenomenon. The proposed model was proved accurate enough for engineering application through verification by indoor experiments.
\end{abstract}

\section{INTRODUCTION}

During the development of gas reservoir, the carrying ability of the gas flow diminishes with the gradual decline of reservoir pressure. If this trend continues, the reservoir liquid cannot be drained but accumulates in the well. In severe conditions, liquid loading may kill the well. Thus, it is meaningful to determine the dynamics of liquid-carrying gas flow for the rational development of the gas well.

The most common method for loading situation determination is to compare the critical liquid-carrying gas flow with the actual gas volume. However, the majority of critical models of droplet or liquid film are built for vertical well through force analysis, rather than horizontal well with a complex structure. The vertical well consists of a straight section, an inclined section and a horizontal section. These sections differ greatly in liquid-carrying mechanics. If applied directly to horizontal well, the conventional critical models cannot accurately compute the critical liquid-carrying gas flow rate.

In light of the above, this paper conducts indoor experiments on actual horizontal gas wells, and establishes a model for the critical liquid-carrying gas flow in the inclined section. The research findings illustrate the dynamics of liquid-carrying gas flow and shed new light on liquid drainage in this type of well.

\section{PREPARATIONS}

\subsection{Test device}

To compare the liquid-carrying gas volume of different sections in horizontal gas well, a multi-phase pipe flow test device was designed for experiments on liquid-carrying gas at different inclined angles. The device consists of an air compressor, a liquid pump, an oil-gas multi-phase flow simulation test tube, a console, etc. It is capable of simulating the oil-gas-water three-phase flow in $0 \sim 90^{\circ}$ pipe and recreating flow patterns ranging from bubble flow to mist flow (Figure 1). With this test device, numerous parameters of multi-phase liquid in the pipe can be measured through experiments, including but not limited to flux, pressure, pressure drop and phase fraction.

During the experiments, the device was used together with an $\mathrm{E}+\mathrm{H}$ type gas flowmeter (accuracy: $\pm 1 \%$ ), an $\mathrm{E}+\mathrm{H}$ type liquid flowmeter (accuracy: $\pm 3 \%$ ), and a Ross Monte differential pressure sensor (accuracy: 0.25\%). The experiments were carried out on air and water media at the normal temperature. The test tube is $8 \mathrm{~m}$ in length and $30 \mathrm{~mm}$ in diameter. The pipe angle was adjusted from $15^{\circ}$ to $90^{\circ}$. The data were recorded when the pressure reached a relative equilibrium. For repeatability, each set of test data were measured through at least five tests.

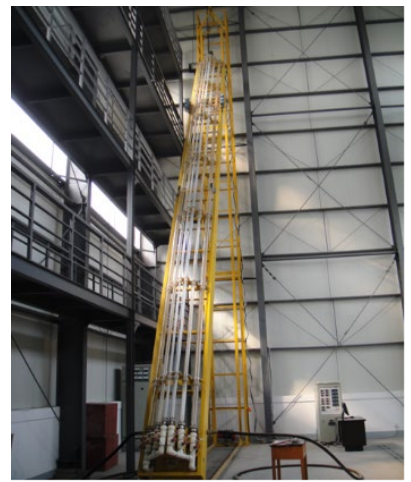

Figure 1. Experimental device

\subsection{Loading section analysis}

Horizontal gas well is more likely to suffer from liquid loading than vertical well, due to its special well structure. 
During gas production, the liquid from the production layer has to pass through a horizontal section, an inclined section and a vertical section to reach the wellhead of horizontal gas well. Below is an analysis to identify the section most prone to liquid loading in horizontal well.

The horizontal section and the inclined section differ in the energy loss per unit height of the upward migration of the liquid. In the inclined section, the liquid-carrying gas flow needs to overcome the shear stress and gravity, similar to the situation in the vertical section. However, additional energy is lost as the gas flow is forced to hit the wall due to the obvious change of the passage in the inclined section. The resulting gas-liquid turbulence and interaction will cause further energy loss. Therefore, under the same flow conditions, the gas flow in the inclined section has weaker liquid-carrying ability than that in the vertical section. In the horizontal section, the laminar flow appears when the liquid and gas volumes reach a certain threshold. In this case, the gas flow can carry liquid as long as its rate is sufficiently fast to overcome the shear stress from the gas-liquid interface on the pipe wall.

Through the above analysis, it is concluded that the gas volume required to carry liquid is smaller in the horizontal section than in the vertical section, while the gas flow in the inclined section has the weakest liquid-carrying ability.

Next, the author carried out several experiments on gaswater two-phase flow in a pipe at different inclined angles and liquid flow rates, and recorded the phenomena and data of liquid carrying under these conditions. The minimum gas volumes required to carry liquid at different liquid flow rates are presented in Figure 2 below.

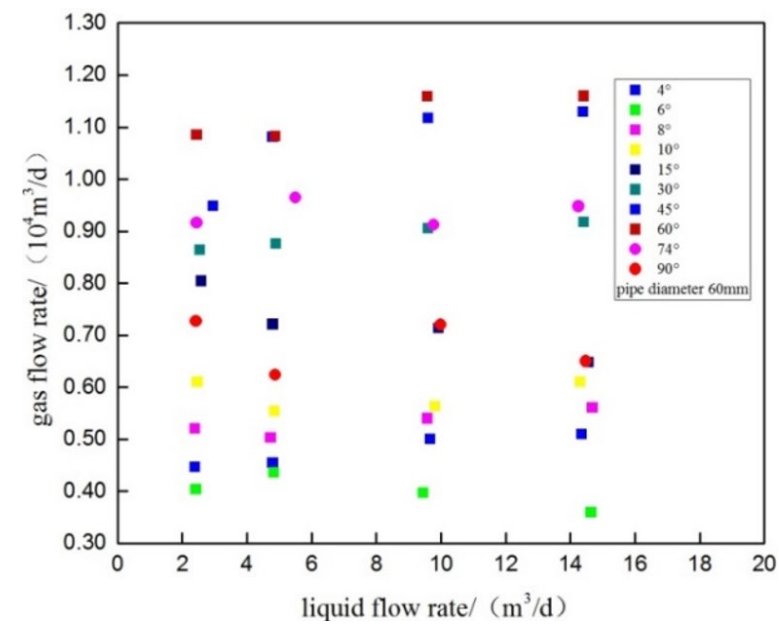

Figure 2. Minimum gas flow required for liquid carrying under different degrees and liquid flow

It can be seen from Figure 2 that the gas flow volume required to carry liquid without falling back varied with pipe inclined angles and liquid flow rates. When the inclined angle fell between $45^{\circ}$ and $60^{\circ}$, the required volume of gas flow reached the maximum level, indicating that this range is the most likely part for liquid loading in the inclined section. This also explains why the gas flow in the inclined section has the weakest liquid-carrying ability.

Hence, it is certain that the inclined section is the most difficult section of horizontal gas well to carry liquid, while the other two sections follow the same liquid-carrying principle as vertical well. Thus, the critical liquid-carrying model of this section should suffice for the study on the liquidcarrying mechanism of the entire horizontal gas well.

\section{CRITICAL LIQUID-CARRYING MODEL FOR HORIZONTAL GAS WELL}

\subsection{Existing models}

The liquid loading analysis is the precondition of liquid drainage of gas wells. The existing mathematical models on liquid loading fall into two categories: droplet model and liquid film model [1].

(1) Droplet model

The droplet model considers droplet as the main form of liquid in well pipe, and assumes that the minimum gas volume for unloading is the volume to carry the largest droplet in the pipe continuously. The typical droplet models include Turner model [2], Coleman model [3], Nosseir model [4] and Li Min model [5].

(2) Liquid film model

The liquid film model attributes liquid loading to the presence of liquid films. It is assumed that the upward movement of the liquid film has to overcome the gravity and the shear stress from the gas-liquid interface on the pipe wall. The typical examples of liquid film model include Kutateladze-Richter model [6], Wallis model [7], KelvinHelmholtz model [8, 9] and Wang Qi model [10].

To sum up, most critical liquid-carrying models only apply to vertical well or the vertical section of horizontal well. The angle terms must be modified before implementing these models for the inclined section. Owing to the lack of mature theories on liquid-carrying mechanism in the inclined section, even the modified models cannot reflect the exact critical liquid-carrying flux, failing to guide the gas production of horizontal well.

\subsection{Critical liquid-carrying model for inclined section}

As mentioned before, the gas flow in the inclined section has the weakest liquid-carrying ability. In this section, the gasliquid two-phase flow changes periodically from slug flow to fracture flow and to slug flow again. Through single-pipe indoor experiments, it is learned that the inclined section could continuously discharge liquid, and the two-phase flow obeyed the periodic slug flow pattern (Figure 3). Therefore, it is practical to set up a critical liquid-carrying model for inclined section based on periodic slug flow.

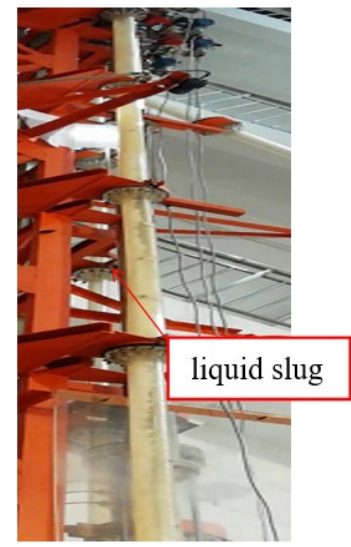

Figure 3. Flow pattern in critical state of liquid carrying at 60 degree in inclined section

(1) Modelling

(a) Critical liquid-carrying model for inclined section 
The liquid-carrying model of the inclined section (Figure 4) was established based on the periodic slug flow. The drop of the liquid plug $\left(L_{S}\right)$ is the main cause of the effusion. The upward movement of the liquid slug is the combined outcome of the pressure drop, air cavity impetus $\left(L_{F}\right)$, fractional force of gas and liquid film, gravity and fractional force of pipe.

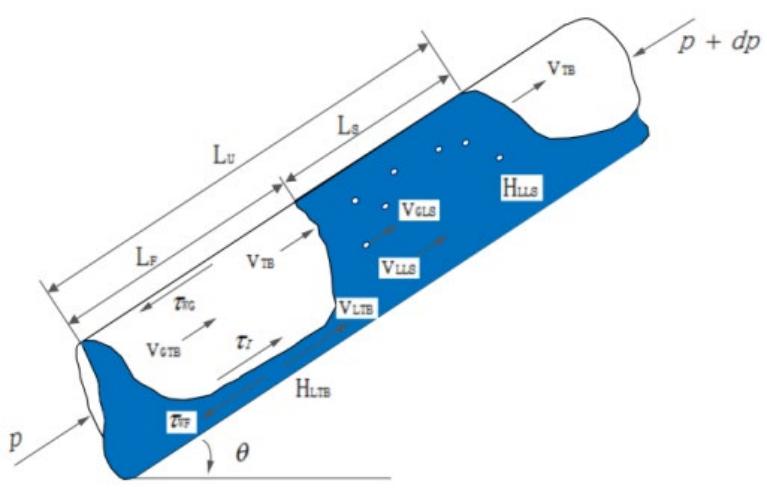

Figure 4. Slug flow model of inclined section

Inspired by Gomez et al. [11-12], a slug in the inclined section was taken as a unit. In this case, the mass equilibrium equations of gas and liquid per unit can be expressed as:

$v_{S L}=v_{L L S} H_{L L S} \frac{L_{S}}{L_{U}}+v_{L T B} H_{L T B} \frac{L_{F}}{L_{U}}$

$v_{S G}=v_{G L S}\left(1-H_{L L S}\right) \frac{L_{S}}{L_{U}}+v_{G T B}\left(1-H_{L T B}\right) \frac{L_{F}}{L_{U}}$

where $v_{S L}$ and $v_{S G}$ are the superficial velocity of liquid and gas, respectively $(\mathrm{m} / \mathrm{s}) ; H_{L L S}$ is the liquid holdup per unit; $H_{L T B}$ is the liquid holdup in the cavity per unit; $v_{L L S}, v_{L T B}, v_{G L S}$ and $v_{G T B}$ are the actual velocity of liquid slug, liquid film in gas cavity, gas in liquid slug and gas cavity, respectively, $(\mathrm{m} / \mathrm{s})$; $L_{U}, L_{S}$ and $L_{F}$ are the length per unit, a liquid plug and a gas cavity per unit, respectively $(\mathrm{m})$.

Similarly, the mass exchange on the interface between liquid plug and gas cavity can be expressed as:

$\left(v_{T B}-v_{L L S}\right) H_{L L S}=\left(v_{T B}-v_{L T B}\right) H_{L T B}$

where $v_{T B}$ is the velocity of slug unit along the production direction ( $\mathrm{m} / \mathrm{s})$. According to Bendiksen et al. [13], the $\mathrm{v}_{\mathrm{TB}}$ for the slug flow in the inclined section can be calculated as:

$v_{T B}=C_{0} v_{M}+(0.542 \cos \theta+$

$0.351 \sin \theta) \sqrt{g\left(\rho_{L}-\rho_{g}\right) D / \rho_{L}}$ where $\mathrm{C} 0$ is dependent on the inclined angle. According to Alves et al. [14], the values of $\mathrm{C}_{0}$ at different inclined angles are as follows: $1.05\left(10^{\circ} \sim 50^{\circ}\right), 1.15\left(50^{\circ} \sim 60^{\circ}\right)$ and $1.25\left(60^{\circ}\right.$ $\sim 90^{\circ}$ )

As suggested by Brotz et al. [15], the relationship between $v_{L T B}$ and $H_{L T B}$ can be established as:

$v_{L T B}=-9.916 \sqrt{\mathrm{g} D\left(1-\sqrt{H_{L T B}}\right)}$

Besides, $v_{G L S}$ can be estimated by:

$v_{G L S}=C_{0} v_{M}+C_{S}\left[\frac{\mathrm{g}\left(\rho_{L}-\rho_{\mathrm{g}}\right) \sigma}{\rho_{L}^{2}}\right]^{0.25} \sqrt{\sin \theta}$

The value of $\mathrm{C}_{\mathrm{s}}$ can be set as 1.41 according to Chokshi et al. [16].

As recommended by Kaya et al. [17], the value of $\mathrm{H}_{\mathrm{LLS}}$ can be calculated as:

$H_{L L S}=1-\frac{v_{S G}}{1.208 v_{M}+1.41\left[\frac{\mathrm{g}\left(\rho_{L}-\rho_{\mathrm{g}}\right) \sigma}{\rho_{L}^{2}}\right]^{0.25} \sqrt{\sin \theta}}$

The continuity equation of gas and liquid at the crosssection can be obtained as:

$v_{M}=v_{S L}+v_{S G}=v_{L L S} H_{L L S}+v_{G L S}\left(1-H_{L L S}\right)$

The per unit liquid holdup can be established as follows based on the physical model of Gomez et al. [11]:

$H_{L U}=\frac{H_{L L S} L_{S}+H_{L T B} L_{F}}{L_{U}}$

The per unit liquid holdup equation can be derived from Equations (2) (8) as:

$H_{L U}=\frac{v_{T B} H_{L L S}+v_{G L S}\left(1-H_{L L S}\right)-v_{S G}}{v_{T B}}$

(b) Experimental fitting of liquid holdup in inclined section (1) Liquid holdup fitting in lab conditions

Six popular multi-phase flow computing methods, namely, BeggsBrill method, Mukherjee Beggs method, Aziz method, Hasan method, JPI method and Orkiszewski method, were experimentally validated (Table 1) for the prediction of liquid holdup and pressure drop of multi-phase pipe flow. BeggsBrill method and the Mukherjee-Brill, were verified for liquid holdup prediction (Table 2).

Table 1. Six methods of pressure gradient prediction average error statistics

\begin{tabular}{ccccccc}
\hline Angles $/\left(^{\circ}\right)$ & Beggs-Brill & Mukherjee & Aziz & Hasan & JPI & Orkiszewski \\
\hline 0 & 0.53 & 0.69 & 39.91 & 1.66 & 1.84 & 0.78 \\
0 & 0.63 & 0.74 & 24.21 & 2.45 & 2.08 & 0.69 \\
0 & 0.66 & 0.77 & 22.08 & 2.05 & 1.81 & 0.66 \\
30 & 0.44 & 0.66 & 0.99 & 0.50 & 0.51 & 0.86 \\
30 & 0.44 & 0.65 & 0.47 & 0.48 & 0.55 & 0.89 \\
30 & 0.46 & 0.61 & 0.63 & 0.49 & 0.50 & 0.87 \\
60 & 0.37 & 0.64 & 0.34 & 0.47 & 0.55 & 0.89 \\
60 & 0.38 & 0.61 & 0.32 & 0.44 & 0.51 & 0.87 \\
90 & 0.37 & 0.56 & 0.27 & 0.39 & 0.42 & 0.85 \\
90 & 0.36 & 0.55 & 0.24 & 0.39 & 0.41 & 0.83 \\
90 & 0.42 & 0.60 & 0.32 & 0.43 & 0.48 & 0.86 \\
\hline
\end{tabular}


Table 2. Two methods of liquid holdup prediction average error statistics

\begin{tabular}{cccccc}
\hline Angles $/\left(^{\circ}\right)$ & Beggs-Brill & Mukherjee & Angles $/\left(^{\circ}\right)$ & Beggs-Brill & Mukherjee \\
\hline 0 & 0.62 & $\mathbf{0 . 7 4}$ & 0 & 0.56 & $\mathbf{0 . 6 3}$ \\
0 & 0.66 & $\mathbf{0 . 7 2}$ & 0 & 0.58 & $\mathbf{0 . 6 6}$ \\
30 & 0.42 & $\mathbf{0 . 5 9}$ & 30 & 0.39 & $\mathbf{0 . 5 7}$ \\
30 & 0.38 & $\mathbf{0 . 5 7}$ & 30 & 0.40 & $\mathbf{0 . 5 2}$ \\
60 & 0.39 & $\mathbf{0 . 6 1}$ & 60 & 0.35 & $\mathbf{0 . 6 1}$ \\
60 & 0.34 & $\mathbf{0 . 6 1}$ & 60 & 0.40 & $\mathbf{0 . 5 5}$ \\
90 & 0.25 & $\mathbf{0 . 4 9}$ & 90 & 0.44 & $\mathbf{0 . 6 2}$ \\
90 & 0.43 & $\mathbf{0 . 6 1}$ & 90 & 0.44 & $\mathbf{0 . 6 1}$ \\
\hline
\end{tabular}

The pressure drop was predicted under four different combinations. As shown in Tables 3 and 4, combination A refers to the prediction of liquid holdup, flow pattern and pressure drop; combination B stands for the prediction of flow pattern and pressure drop under known liquid holdup; combination $\mathrm{C}$ means the prediction of liquid holdup and pressure drop under known liquid holdup; D involves the prediction of pressure drop under known liquid holdup and flow pattern.

Table 3. Average error statistics of pressure drop prediction under different combination conditions of Beggs-Brill method

\begin{tabular}{cccccccccc}
\hline Angles $/\left({ }^{\circ}\right)$ & $\mathrm{A}$ & $\mathrm{B}$ & $\mathrm{C}$ & $\mathrm{D}$ & Angles $/\left(^{\circ}\right)$ & $\mathrm{A}$ & $\mathrm{B}$ & $\mathrm{C}$ & $\mathrm{D}$ \\
\hline 0 & 0.535 & $\mathbf{0 . 5 9 9}$ & 0.552 & 0.599 & 0 & 0.656 & $\mathbf{0 . 6 9 8}$ & 0.665 & 0.698 \\
30 & 0.445 & $\mathbf{0 . 2 1 4}$ & 0.577 & 0.214 & 30 & 0.457 & $\mathbf{0 . 2 0 7}$ & 0.607 & 0.207 \\
60 & 0.408 & $\mathbf{0 . 1 5 3}$ & 0.493 & 0.153 & 60 & 0.381 & $\mathbf{0 . 1 4 5}$ & 0.550 & 0.145 \\
90 & 0.248 & $\mathbf{0 . 2 2 4}$ & 0.380 & 0.224 & 90 & 0.371 & $\mathbf{0 . 2 1 0}$ & 0.507 & 0.210 \\
0 & 0.630 & $\mathbf{0 . 6 6 8}$ & 0.644 & 0.668 & 0 & 0.629 & $\mathbf{0 . 6 7 3}$ & 0.640 & 0.673 \\
30 & 0.444 & $\mathbf{0 . 2 3 6}$ & 0.625 & 0.236 & 30 & 0.432 & $\mathbf{0 . 2 2 0}$ & 0.600 & 0.220 \\
60 & 0.374 & $\mathbf{0 . 1 3 5}$ & 0.635 & 0.135 & 60 & 0.401 & $\mathbf{0 . 1 3 2}$ & 0.544 & 0.132 \\
90 & 0.357 & $\mathbf{0 . 1 9 5}$ & 0.490 & 0.195 & 90 & 0.424 & $\mathbf{0 . 1 7 8}$ & 0.543 & 0.178 \\
\hline
\end{tabular}

Table 4. Average error statistics of pressure drop prediction under different combination conditions of Mukherjee-Brill method

\begin{tabular}{cccccccccc}
\hline Angles $/\left({ }^{\circ}\right)$ & $\mathrm{A}$ & $\mathrm{B}$ & $\mathrm{C}$ & $\mathrm{D}$ & Angles $\left./{ }^{\circ}\right)$ & $\mathrm{A}$ & $\mathrm{B}$ & $\mathrm{C}$ & $\mathrm{D}$ \\
\hline 0 & 0.688 & $\mathbf{0 . 6 1 0}$ & 0.690 & 0.694 & 0 & 0.769 & $\mathbf{0 . 5 7 1}$ & 0.770 & 0.770 \\
30 & 0.657 & $\mathbf{0 . 2 2 5}$ & 0.656 & 0.225 & 30 & 0.607 & $\mathbf{0 . 2 1 5}$ & 0.607 & 0.215 \\
60 & 0.630 & $\mathbf{0 . 1 6 3}$ & 0.630 & 0.163 & 60 & 0.611 & $\mathbf{0 . 1 5 0}$ & 0.611 & 0.150 \\
90 & 0.455 & $\mathbf{0 . 2 5 9}$ & 0.455 & 0.260 & 90 & 0.563 & $\mathbf{0 . 2 0 7}$ & 0.563 & 0.207 \\
0 & 0.745 & $\mathbf{0 . 7 4 0}$ & 0.745 & 0.740 & 0 & 0.747 & $\mathbf{0 . 7 4 8}$ & 0.748 & 0.748 \\
30 & 0.646 & $\mathbf{0 . 2 4 4}$ & 0.646 & 0.244 & 30 & 0.612 & $\mathbf{0 . 2 2 7}$ & 0.611 & 0.227 \\
60 & 0.636 & $\mathbf{0 . 1 4 2}$ & 0.635 & 0.142 & 60 & 0.590 & $\mathbf{0 . 1 3 7}$ & 0.590 & 0.137 \\
90 & 0.552 & $\mathbf{0 . 1 9 5}$ & 0.552 & 0.195 & 90 & 0.601 & $\mathbf{0 . 1 8 0}$ & 0.601 & 0.180 \\
\hline
\end{tabular}

The liquid holdup was predicted under combinations A and $\mathrm{C}$ using Beggs-Brill method and Mukherjee-Brill method. The prediction results are displayed in Tables 5 and 6 .

Table 5. Average error statistics of liquid holdup prediction under different combination conditions of Beggs-Brill method

\begin{tabular}{cccccc}
\hline Angles $/\left(^{\circ}\right)$ & $\mathrm{A}$ & $\mathrm{C}$ & Angles $/\left(^{\circ}\right)$ & $\mathrm{A}$ & $\mathrm{C}$ \\
\hline 0 & 0.617 & 0.557 & 0 & 0.560 & 0.511 \\
15 & 0.407 & 0.510 & 15 & 0.412 & 0.495 \\
30 & 0.417 & 0.490 & 30 & 0.395 & 0.580 \\
45 & 0.449 & 0.419 & 45 & 0.413 & 0.431 \\
60 & $\mathbf{0 . 3 8 7}$ & $\mathbf{0 . 4 5 9}$ & 60 & $\mathbf{0 . 3 5 0}$ & $\mathbf{0 . 5 4 5}$ \\
90 & 0.254 & 0.459 & 90 & 0.444 & 0.570 \\
0 & 0.660 & 0.607 & 0 & 0.577 & 0.515 \\
30 & 0.381 & 0.542 & 30 & 0.397 & 0.512 \\
60 & $\mathbf{0 . 3 4 2}$ & $\mathbf{0 . 6 0 5}$ & 60 & $\mathbf{0 . 4 0 1}$ & $\mathbf{0 . 4 9 6}$ \\
90 & 0.426 & 0.551 & 90 & 0.442 & 0.550 \\
\hline
\end{tabular}

As shown in Tables 5 and 6, the Beggs-Brill method led to a large error in the prediction of the inclined section under combinations $\mathrm{A}$ and $\mathrm{C}$. When the flow pattern is known, the relative error of the Beggs-Brill method in liquid holdup prediction fluctuated greatly, while that of the Mukherjee-Brill method (the bold data in Table 6) remained basically the same.
Table 6. Average error statistics of liquid holdup prediction under different combination conditions of Mukherjee-Brill method

\begin{tabular}{cccccc}
\hline Angles $/\left({ }^{\circ}\right)$ & $\mathrm{A}$ & $\mathrm{C}$ & Angles $/\left(^{\circ}\right)$ & $\mathrm{A}$ & $\mathrm{C}$ \\
\hline $\mathbf{0}$ & $\mathbf{0 . 7 3 8}$ & $\mathbf{0 . 7 3 8}$ & $\mathbf{0}$ & $\mathbf{0 . 6 3 0}$ & $\mathbf{0 . 6 3 0}$ \\
30 & 0.588 & 0.588 & 30 & 0.574 & 0.574 \\
60 & 0.611 & 0.611 & 60 & 0.607 & 0.607 \\
90 & 0.493 & 0.493 & 90 & 0.621 & 0.621 \\
\hline
\end{tabular}

It can be seen from Tables 1 and 2 that all these methods had a poor accuracy in the prediction of liquid holdup and pressure drop, with the minimum error of $49 \%$. Moreover, the prediction was relatively accurate in situation $\mathrm{B}$, indicating that the prediction effect of pressure drop in the inclined pipe hinges on the accuracy of the liquid holdup forecast.

It can also be seen from Table 6 that the predicted result of the horizontal section differed greatly from that of the inclined section. Hence, the Mukherjee-Brill method was refitted under the critical condition for the airflow in the inclined section to carry liquid, using the data of the conventional air-water twophase pipe flow experiments at different inclined angles and water contents (pipe diameters: $40 \mathrm{~mm}, 60 \mathrm{~mm}$ and $75 \mathrm{~mm}$ ). In this way, the author obtained a new calculation model for liquid holdup. 
The fitting results of the liquid holdup in inclined section are listed in Table 7 below.

Table 7. The fitting results in inclined section

\begin{tabular}{cccc}
\hline \multirow{2}{*}{ Source } & \multicolumn{3}{c}{ Inclined (include vertical)* } \\
& Sum of squares & $d f$ & Mean square \\
\hline Regression & 24.899 & 10 & 2.490 \\
Residual & .491 & 761 & .001 \\
Uncorrected statistics & 25.390 & 771 & -- \\
Corrected statistics & 6.052 & 770 & -- \\
*Dependent variable $H_{1}$, a.R square $=0.840$. &
\end{tabular}

After fitting, the liquid holdup calculation formula for the inclined section can be expressed as:

$$
\begin{aligned}
& H_{1}=\exp \left[\left(-0.472+0.111 \sin \theta-0.076 \sin ^{2} \theta+\right.\right. \\
& \left.\left.8.353 \mathrm{~N}_{\mathrm{l}}^{2}\right) \frac{\mathrm{N}_{\mathrm{vg}}^{0.369}}{\mathrm{~N}_{\mathrm{vl}}^{0.044}}\right]
\end{aligned}
$$

where $\mathrm{N}_{l}=\mu_{L}\left[\mathrm{~g} /\left(\rho_{L} \sigma^{3}\right)\right]^{0.25}$;

$\mathrm{N}_{v g}=v_{v g}\left[\rho_{\mathrm{g}} /(\mathrm{g} \sigma)\right]^{0.25} ; \mathrm{N}_{v l}=v_{v l}\left[\rho_{L} /(\mathrm{g} \sigma)\right]^{0.25}$.

(2) Error analysis of fitting calculation formula

The new model, fitted against the experimental data, should be tested to see if it conforms to the experimental data. Here, the correctness of the fitting process is verified and then the new model was validated against field measured data. The mean error of the predicted liquid holdup and pressure drop are compared with the experimental data in Table 8.

Table 8. New model prediction results and experimental data average error statistics

\begin{tabular}{cccc}
\hline Angles $/\left(^{\circ}\right)$ & $\begin{array}{c}\text { Liquid holdup } \\
\text { predicting value }\end{array}$ & $\begin{array}{c}\text { Liquid holdup } \\
\text { experimental value }\end{array}$ & $\begin{array}{c}\text { average } \\
\text { error }\end{array}$ \\
\hline 30 & 0.078 & 0.086 & 0.093 \\
60 & 0.134 & 0.120 & 0.117 \\
90 & 0.240 & 0.218 & 0.101 \\
\hline
\end{tabular}

Compared with Tables 1, 2, 4 and 6, Table 8 shows a marked improvement of the prediction accuracy for liquid holdup and pressure drop. The bold data in Table 8 reveal that the prediction accuracy increased greatly in the sections other than the horizontal section. In the inclined and vertical sections, the new model achieved the prediction accuracy required for engineering purposes.

Table 8 also demonstrates that the prediction accuracy of pressure drops only increased slightly after the fitting, as the pressure drop of the horizontal section is dominated by the frictional term, and that the new model could calculate the liquid holdup of the inclined section when the inclined angle fell between $0^{\circ}$ and $90^{\circ}$.

(2) Experimental verification

Based on the relationship between the liquid holdup of the inclined section obtained in equation (1) and fitted in equation (2), the critical liquid-carrying model for certain gas flow in the inclined section can be expressed as:

$$
\begin{aligned}
& \frac{v_{T B} H_{L L S}+v_{G L S}\left(1-H_{L L S}\right)-v_{S G}}{v_{T B}}=\exp [(-0.472+0.111 \sin \theta- \\
& \left.\left.0.076 \sin ^{2} \theta+8.353 \mathrm{~N}_{1}^{2}\right) \frac{N_{v g}^{c_{5}}}{N_{v L}^{c_{6}}}\right]
\end{aligned}
$$

The parameters of the above equation were calculated by the trial method. With this equation, the critical gas flow rate was finally determined. The established mathematical model was tested and perfected by the indoor experiment, and its results were compared with the measured values. The relative error is illustrated in Figure 5 below.

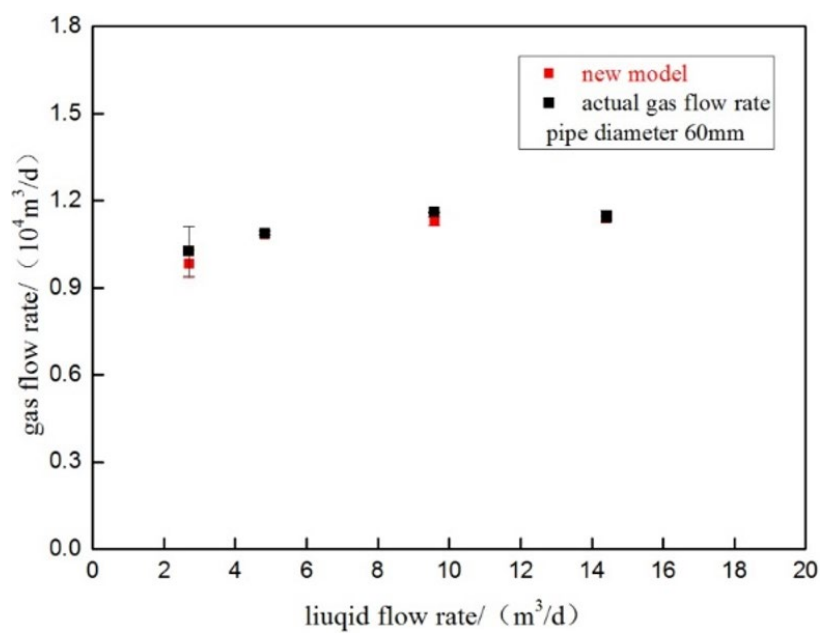

Figure 5. Calculation and comparison of critical model for inclined sections

As shown in Figure 5, the mean error was merely $3.99 \%$, an evidence of the good agreement between the values of the proposed model and the experimental data. Hence, the model satisfies the accuracy required for engineering projects.

\section{CONCLUSIONS}

(1) Through single pipe indoor experiments on gas-water two-phase flow, it is confirmed that the inclined section (inclined angle: $45^{\circ} \sim 60^{\circ}$ ) is mostly likely to suffer from liquid loading in horizontal gas well.

(2) The liquid-carrying phenomenon differs greatly between the different sections of horizontal gas well. In the inclined section, the slug flow dominates the liquid-carrying mode.

(3) The author set up a critical liquid-carrying rate model for the inclined section according to the mass conservation principle and the fitted liquid holdup calculation model. The experimental results show that the proposed model can accurately predict the critical status of liquid-carrying phenomenon in horizontal gas well, as the prediction error is merely $3.99 \%$.

\section{ACKNOWLEDGEMENT}

Supported Funds: National Natural Science Fund Project (Grant No.61572084), 13th Five-Year Major National Major Projects (Grant No.2017ZX05030-005).

\section{REFERENCES}

[1] Morgado AO, Miranda JM, Araújo JDP, Campos JBLM. (2016). Review on vertical gas-liquid slug flow. International Journal of Multiphase Flow 85: 348-368. http://dx.doi.org/10.1016/j.ijmultiphaseflow.2016.07.00 2

[2] Li M, Guo P, Liu W, Zhang ML, Li SL. (2002). Comparative study of continuous-removal liquid models 
from gas well. Fault-Block Oil \& Gas Field 9(6): 39-41. http://dx.doi.org/10.3969/j.issn.1005-8907.2002.06.012

[3] Liu GF, He SL, Gu DH. (2006). New model of the critical liquid carrying flow rate for gas wells. Natural Gas Industry 26(10): 114-116.

[4] Wei N, Meng YF, Li YQ. (2008). Research on liquids continuous removal laws in gas well. Drilling \& $\begin{array}{lll}\text { Production } & \text { Technology 31(6): } & 88-90 .\end{array}$ http://dx.doi.org/10.3969/j.issn.1006-768X.2008.06.028

[5] Nosseir MA, Darwich TA, Sayyouh MH. (2000). New approach for accurate prediction of loading in gas wells under different flowing conditions. SPE Production \& Facilities 15(4): 241-246. http://dx.doi.org/10.2118/66540-PA

[6] Li M, Sun L, Li S. (2001). New view on continuousremoval liquids from gas wells. SPE Production \& Facilities 17(01): 42-46. http://dx.doi.org/10.3321/j.issn:1000-0747.2001.05.031

[7] Ji HJ. (2008). Counter-current flow limitation velocity measured in annular narrow gaps formed between large diameter concentric pipes. Korean Journal of Chemical Engineering 25(2): 209-216. http://dx.doi.org/10.1007/s11814-008-0038-x

[8] Wallis GB, Hutchings BJ. (1983). Compressibility effects on waves in stratified two-phase flow. International Journal of Multiphase Flow (3): 325-336. http://dx.doi.org/10.1016/0301-9322(83)90110-6

[9] Wood BD, Radakovich K, Golfier F. (2007). Effective reaction at a fluid - solid interface: Applications to biotransformation in porous media. Advances in Water Resources $30(6)$ : $1630-1647$ http://dx.doi.org/10.1016/j.advwatres.2006.05.032

[10] Huang Z, Xiao ZJ, Yan X. (2017). Centrifugal force effect on film interfacial instability on the wall of cyclone separator. Nuclear Science and Engineering 37(5): 761 767.

[11] Wang Q. (2014). Experimental study on gas-liquid flowing in the wellbore of horizontal well. Chengdu: Southwest Petroleum University.

[12] Ahmadi MA, Galedarzadeh M, Shadizadeh SR. (2016). Low parameter model to monitor bottom hole pressure in vertical multiphase flow in oil production wells. Petroleum 2(3): 258-266. http://dx.doi.org/10.1016/j.petlm.2015.08.001

[13] Xue JL, Luo W, Liu ZL, Wu ZH, Wang JL, Liao RQ. (2018). A criterion of negative frictional pressure drop in vertical two- phase flow. Chemical Engineering Transactions 66: 415-420. http://dx.doi.org/10.3303/CET1866070

[14] Fabre J, Line A. (2003). Modeling of two-phase slug flow. Annual Review of Fluid Mechanics 24(1): 21-46. http://dx.doi.org/10.1146/annurev.fl.24.010192.000321

[15] Alves I. (1991). Slug Flow Phenomena In Inclined Pipes. Oklahoma: University of Tulsa.

[16] Morgado AO, Miranda JM, Araújo JDP. (2016). Review on vertical gas-liquid slug flow. International Journal of Multiphase $\quad$ Flow 85: 348-368. http://dx.doi.org/10.1016/j.ijmultiphaseflow.2016.07.00 2

[17] Chokshi R. (1994). Prediction of pressure drop and liquid holdup in vertical two-phase flow tubing. University of Tulsa: Master Dissertation: 41-6.

[18] Kaya AS, Sarica C, Brill JP. (2001). Mechanistic modeling of two-phase flow in deviated wells. SPE Production \& Facilities 16(3): 156-65. http://dx.doi.org/10.2118/72998-PA 